\title{
THREE-STEP EXPERIMENTATION ON EMBEDDING CURVATURE TO RIGID PLANAR MATERIALS THROUGH CUT PATTERNS
}

\author{
EXPERIMENTAÇÃO DE TRÊS PASSOS EM INCORPORAÇÃO DE \\ CURVATURA DE MATERIAIS DE SUPERFÍCIE PLANAR RÍGIDOS \\ POR MEIO DE PADRÕES DE CORTE
}

\section{Orkan Zeynel Güzelci', Sema Alaçam², Saadet Zeynep Bacınoğlu²}

RESUMO: Este estudo apresenta resultados e descobertas de uma experimentação de três passos para integrar técnicas de modelagem e design analógico e digital, com especial atenção para o aumento do rendimento do comportamento de curvatura e curvilinearidade dos materiais de superfície planar rígidos. No âmbito do processo de experimentação, o papelão foi utilizado como material, as ações de corte e flexão foram utilizadas como técnicas e o corte a laser e o ambiente de script visual foram envolvidos como ferramentas. São examinados os potenciais de técnicas de materiais subtraíveis, tais como operações de corte, curvatura, incisão. A experimentação abrange a geração de padrão, incorporação de padrões de corte ao material plano 2D e remapeamento de padrões 2D em superfícies 3D, com base nos conhecimentos adquiridos na fase anterior e na exploração de novas superfícies de forma livre em 3D tanto em ambientes físicos como digitais. O modelo de experimentação de três passos apresentado tem potenciais para contribuir com os estudos pedagógicos focados nas abordagens exploratórias e criativas para a formação e fabricação de projetos integrativos.

PALAVRAS-CHAVE: Flexão; Criação; Corte a Laser; Fabricação Digital; Técnicas Materiais; Curvatura Dupla.

ABSTRACT: This study presents the outcomes and findings of a three-step experimentation to integrate analog and digital design and modeling techniques, with a particular focus on augmenting the affordance of bending behavior and curvilinearity of rigid planar surface materials. In the scope of the experimentation process, cardboard was used as a material, cutting and bending actions were utilized as techniques and laser cut and visual scripting environment were involved as tools. The potentials of subtractive material techniques such as cut, bend, kerf operations are examined. The experimentation covers hands-on pattern generation, embedment of cut patterns to 2D planar material, re-mapping 2D patterns onto 3D surfaces based on the insights gained in the previous phase and exploration of new 3D freeform surfaces both in physical and digital environments. The three-step experimentation model presented has potentials to contribute to the pedagogical studies focusing on explorative and creative approaches for integrative design formation and fabrication processes.

KEYWORDS: Bending; Making; Laser Cut; Digital Fabrication; Material Techniques; Double Curvature.

\section{How to cite this article:}

GÜZELCI, O. Z.; ALAÇAM, S.; BACINOĞLU, S. Z. Three-step experimentation on embedding curvature to rigid planar materials through cut patterns.Gestão e Tecnologia de Projetos, São Carlos, v. 12, n. 3, p. 93-107 2017. http://dx.doi.org/10.11606/gtp.v12i3.134543 


\section{INTRODUCTION}

The increasingly accessibility and widespread use of digital design and fabrication tools is rapidly transforming the notions of design model and modelling processes. Advances in computational tools have been reflected to the way design ideas were represented, designed and fabricated. In the context of digital design, new gaps have been emerged between the "known" and "knowledge", as a result of the epistemological shift from form to formation, static to dynamic, thinking to making, solid geometry to computable. From the evolutionary point of view, according to Aish (2013), the eras of drafting, information modelling and computational modelling have been experienced. After those eras, in the last decade, debates on matter, materialization, material behavior have become more apparent.

Today, there have been recent researches on Design Fabrication, which integrates material, form and performance aspects reciprocally, in which they inform each other. This integration is merging design and construction, designer and maker, which result with new material properties and unique fabrication techniques that can replace industrially standard materials and construction techniques. Naboni and Pezzi (2016) indicate the necessity of new dialogues between designers and their relationship with materials. It is possible to expand this discussion towards the necessity of new dialogues among designers, tools, methods, techniques and environments not only to explore but also to constitute new knowledge. In other words, an ongoing interaction between designers and design approaches, virtual and real, abstract geometry and concrete experience have potential to bring new possibilities to digital fabrication domain.

On the other hand, the skills and experience that architects need have been changing in the context of digital fabrication. Today, in a constantly changing and floating ground of knowledge, architects need to reposition themselves. Accordingly, new pedagogies need to be investigated, while keeping a constant distance to transformation in technology. It is possible to consider digital fabrication techniques as an exploration space in which knowledge is constructed in the age of digital. In the scope of this study, instead of using already existing digital fabrication techniques precisely, we aim to construct design logic of fabrication based on learning from making experiments.

We argue that revisiting Dewey's transformative experience concept, which has been influential on experiential learning models, might be a key to deal with epistemological crisis of today. Different than learning or teaching a discrete part of existing knowledge, the concept of transformative experience offers three qualitative principles: active use of a concept, an expansion of perception and an expansion of value (Pugh; Girod, 2007).

In the context of digital fabrication, a deeper interaction among design ideas and material and techniques would enrich the experienced qualities of the design process. With those concerns in mind, in the scope of this study, a three-step experimentation to integrate analog and digital design and modeling techniques was held. This model is based on embedding cut patterns to the 2D planar material, translating 3D surfaces to 2D patterns and exploring new 3D free-form surfaces. Respectively, the focus of the studies was on algorithm-dependent pattern generation, the implication of the geometric patterns onto the planar material by using the laser cutter and improvement of the digital model based on explorations gained in previous stages.

Derived from the findings and observations of the experimentation, we propose to use a production technique as a design tool for integrating design and fabrication phases. The production techniques of cutting and bending are adopted as a design tool. Cutting is used to create heterogeneous material properties for designing curvilinear surfaces through bending. Specifically, the study focuses on enriching the affordance of bending behavior and 
curvilinearity of rigid planar surface materials. However, the main emphasis of the study is to the reflective qualities of experience during the design process, rather than merely focusing on material behavior (Greenberg; Körner, 2014) (Figure 4) and structural performance studies (KotelnikovaWeiler et al., 2013). Different than existing studies on integrated design and fabrication processes, this study does not develop a new fabrication technique (Hoffer et al., 2012; Zarrinmehr et al., 2017) or does not provide a nature inspired (Weston, 2012) form finding process. The initial departure points of the experimentation process involve geometrical patterns manually generated by designers. This study aims to acquire insights during the dialogue between the designer and design medium, which will later reflect on further steps. In the scope of the experimentation process, cardboard was used as a material, cutting and bending actions were used as techniques and laser cut and visual scripting environment were involved as tools.

The goals of this study are:

- To enhance the affordance of the rigid planar material by using different cut operations to achieve 3D complex geometrical explorations.

- To create an intuition about the interdependent relationship between material properties and geometry as an active agency of design.

\section{THEORETICAL FOUNDATIONS}

Experiments on the integration of form generation techniques and material behavior are not new issues in architecture. The integration of construction technique and material behavior, however, had been widespread and common before the industrialization era. The maker designer mostly does his/her design relies on tacit tactile knowledge through step by step evaluation, which can be associated with the pedagogical model of "learning by doing” or in Schön's words, "learning in designing” (Schön, 1993). As Ackermann (2007) underlines in relation with Piaget's and Papert's discussions, making and construction are important aspects of learning. Ackermann (2007) also emphasized that "people compose with what is offered by the materials”.

Apart from the precedent studies in ancient history, it is possible to trace back similar investigations in the studios of Moholy-Nagy and Albers in the 1930s Bauhaus (Figure 1). Albers and Moholy-Nagy are one of the well-known educators who teach how to design with the constraints of the material. In this period, craftsmanship had a crucial value in the education curriculum. Moholy-Nagy's quote from Lewis Mumford indicates this tendency: "The machine cannot be used as a short cut to escape the necessity for organic experience” (Moholy-Nagy, 2005). At the same time, dialogue between material and designer was considered as an aesthetic experience in which new qualities can be explored. In Moholy-Nagy's own words: "The woodcutting shows the potentialities of the woodworking machines until now unknown. Solid pieces of wood can be changed into rubber-like elasticity, etc. But what is more amazing is that same principle can be applied to every other material and every other tool" (Moholy-Nagy, 2005).

Last century, new learning pedagogies have emerged in response to machine and designer encounter. Revisiting pedagogical approaches based on experiential learning in active experimentation have potential to contribute to today's epistemological crisis. The digital era, in which designers have been continuously dealing with new tools and techniques, needs to reveal its own craftsmanship. As it has been examined in the earlier $20^{\text {th }}$ century, exploring the potentialities of materials by applying recursive operations keeps its importance today. In other words, seeking 
Figure 1: William Worst Woodcutting by Machine (left), Woodcutting by Bredendieck (right) in 1937

Source: Moholy-Nagy (2005) experimental ways to expand the affordances of material through physical kind of engagements, exploring emergent behaviors of materials through systematic investigation of repetitive and recursive operations have potentials to create new opportunities in the context of pedagogical approaches. In Dewey's words, this attempt can be considered as a "conversational transaction between the designer and the materials of a problematic situation” (Dewey, 1938).

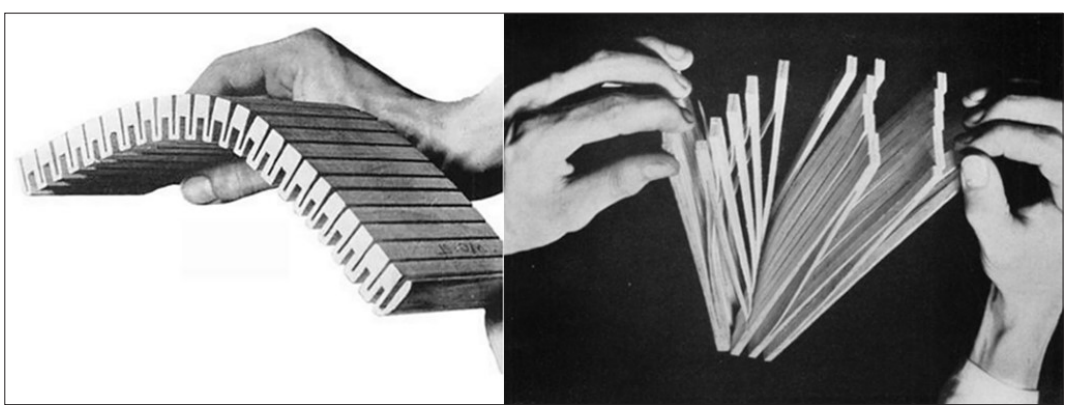

\section{RELATED STUDIES}

The studies that have attempted to empirically explore the potentials of novel digital fabrication approaches in design can be investigated under the titles of form-finding approaches, material studies, advances in computational geometry. However, these axes integrate or overlap in most of the studies. In this part, studies on behavior modeling in the context of material studies, form-finding approaches using subtractive material techniques with a particular focus on cut, bend, kerf operations and studies on algorithmic pattern generation conducted with digital fabrication process are examined.

According to Kotnik and Weinstock (2012), integrating form, material and force introduce a novel generative logic of form finding. As Kotnik and Weinstock (2012) state, material plays an important role to make the form buildable. In many studies, the material is selected after finishing the conceptualization of form. However, we argue that the material, material behaviors, and fabrication techniques are important design aspects in the generation process. These design aspects are increasingly involved in contemporary design processes with the accessibility of digital technologies.
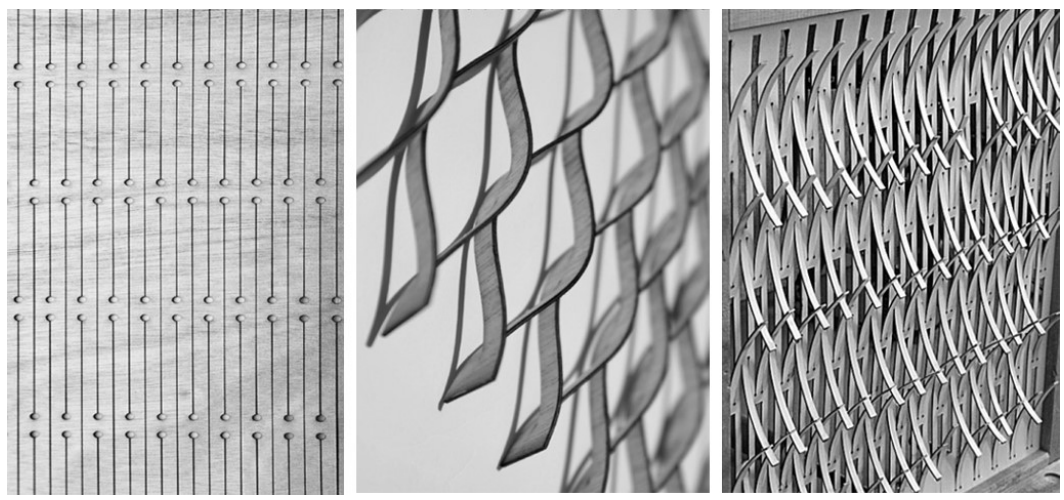

For example, Weston's (2012) experiments on unidirectional material weakening as a means of producing material properties for adjusting solar shading performance of building Figure 2); Schönbrunner et al. (2015) uses cut patterns to transform the initial surface to undulated surfaces 
for controlling the stiffness and self-supporting properties; Hoffer et al. (2012) applies radial kerfing lines onto rigid plywood panels to produce non-standard conic surfaces; D’Acunto and Kotnik (2013) adopts cutting operation to control the bending resistance of the sheets for a larger spatial enclosure and reduced wind load acting upon the structure, and additionally produces a shadow pattern. Hands-on study models of AA/ETH Pavilion and Kerf Pavillion are shown in Figure 3a and Figure 3b.

In the study shown in Figure $3 \mathrm{a}$ and $3 \mathrm{~b}$, complex self-bending behavior has been both tested and analyzed through physical models and computational models. A series of cut operation have applied to planar materials both in study models and end product. The study models have provided feedback to improve computational models. In the final pavilion, the subtraction pattern was applied onto timber material. In that sense, it can be considered as integrated design and fabrication process.

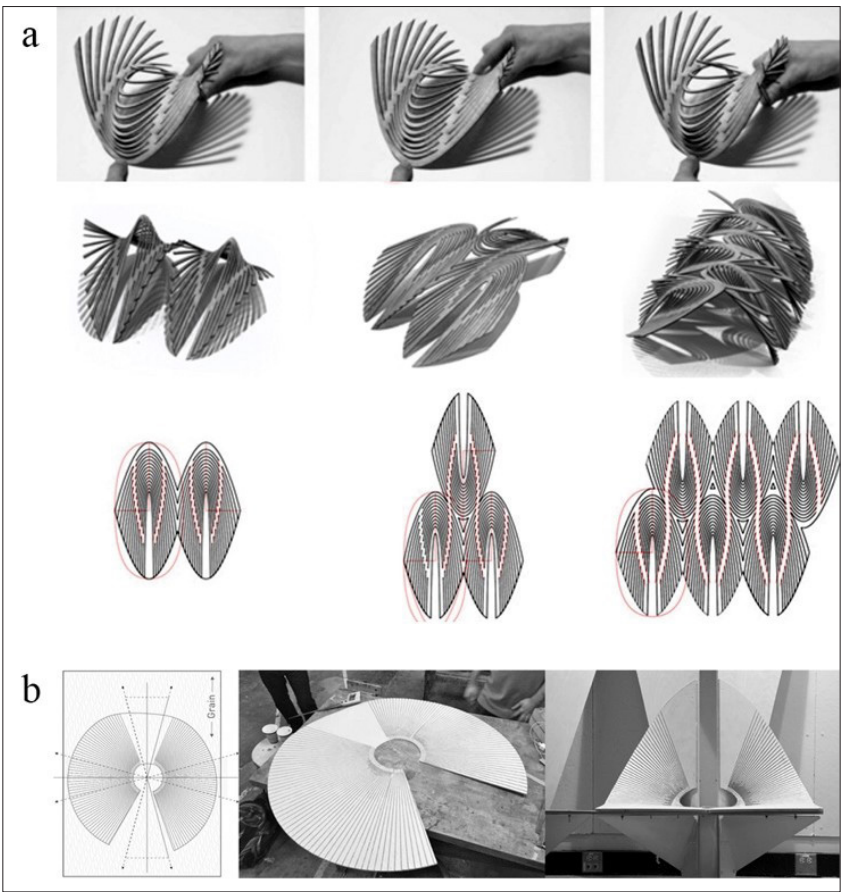

Naboni and Mirante (2016) approached material studies focusing on differentiation of patterns to create auxetic structures. The basic patterns they dealt with are: honeycomb, triangular-based, lozenge-based, sinusoidal, hexagonal shapes. In Naboni and Mirante's (2016) study, the formal affordances of patterns were engaged with auxetic behavior of the materials in which cut patterns were implied, apart from the relations to architectural samples. Muñoz (2013) examined three-dimensional from studies based on cut operations on two-dimensional sheets. The main scope of Muñoz's studies is related to industrial design explorations such as furniture design, accessories, wearable elements (Muñoz, 2013). While Muñoz (2013) has focused on prototype-based products, different than Muñoz's studies we dealt with exploration of three-dimensional study models with different curvatures, relationship between parametric definition of the cut patterns and flexibility conditions of the material.

Outcomes produced during our experiments are study models rather than full-scale prototypes. Moreover, different than kerf cutting or engraving (via laser cut), we experimented with subtractive cut operations. In our study, planar wood materials are examined. The natural wood material has complex behaviors and anisotropic material properties. As we can benefit from natural anisotropic properties of
Figure 3a: Self-weight bending behavior of plywood sheets, AA/ETH Pavilion

Source: D'Acunto and Kotnik (2013)

Figure 3b: Radially Kerfed Plywood Cone Shape, Kerf Pavilion

Source: Hoffer et al. (2012) 
Figure 4: Subtractive Manufacturing for Plywood

Source: Greenberg and Körner (2014) natural (heterogeneous) materials; digital fabrication techniques can embed anisotropic properties into homogeneous materials. In this study, we used homogeneous planar board materials aiming to transform them into anisotropic wood-like material.

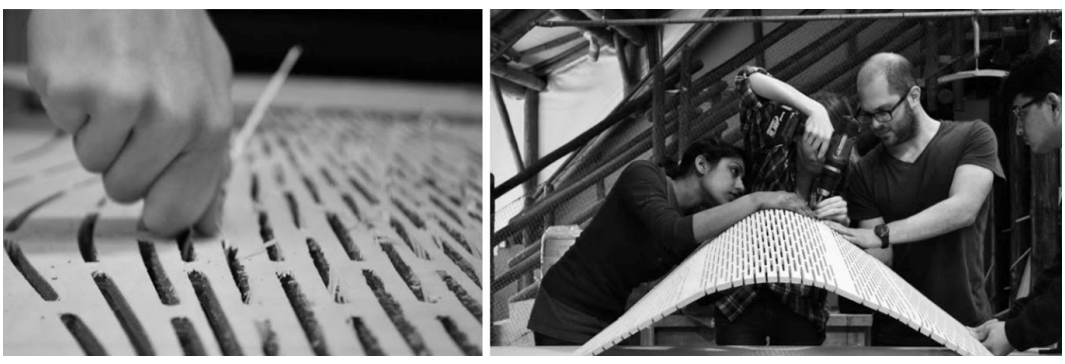

\section{EXPERIMENT SETUP}

We started our study by examining planar wood materials. The natural wood material has complex behaviors and anisotropic material properties. However, medium density fiberboard (MDF), cardboard and Plexiglass can be considered as more common, cheaper and stable physical modeling materials for students. As we can benefit from natural anisotropic properties of natural (heterogeneous) materials; digital fabrication techniques can embed anisotropic properties into homogeneous materials. In this study, we used homogeneous planar board materials aiming to transform them into anisotropic wood-like material. As similar to Weston's method (2012), we introduced unidirectional material weakening to produce different material properties in order to get an intuition of how to create materially complex architectural environments. The unidirectional material weakening is achieved through periodic arrays of a cell with a specific geometry. The pattern made of differentiated cell geometries allows us to control different topology and dimensional characteristics.

The scope of our experimentation covers hands-on exploration, single material, three-dimensional model in Rhinoceros modeling environment, two-dimensional geometric pattern algorithm in Grasshopper visual programming environment, and implication of geometric surface patterning through operations of cut and bend.

We started our experiment setup with four different cut patterns on MDF (medium density fiberboard) materials and observed the material's flexibility through changing parameters (Figure 5). The applied subtractive cut operations are different than kerf cutting or engraving via laser cut. The patterns that are cut have two different types of parameters. One is operational; the other is numerical/geometric relations and properties. By varying the geometric parameters as well as $\mathrm{dx}$ and dy distances and the repeating shapes in the patterns, it is possible to add numerous local and global characteristics such as elasticity. Besides, not only the thickness of the material but also the position, direction, and pressure forced of hands-on operations influence the rigidity and the resulted form, hence the Gaussian curvature of the surface.

Assumptions and variables of experiment setup are listed below:

- Size: The size of the planar cardboard material is limited as $10 \times 18 \mathrm{~cm}$.

- Thickness: The thicknesses of materials are 1 and 2 millimeters.

- Pattern property: The four types (Figure 5) of the repetitive patterns applied to material via laser cutter

- Level of porosity of the surface: The ratio of void area to solid area after the cutting operation. 
- Bending behavior of the material: The maximum curvature of planar surface without being broken under the force of gravity and other external forces.

- Behavior: The possible formal reactions of the material to the bending operation during hands-on exploration from different pivot points.

- Translation: $\mathrm{dx}$ and dy are assumed to represent the distance between units in $\mathrm{X}$ and $\mathrm{Y}$ directions.

- Cut: Cut operations can be used to modify the porosity level of surface and flexibility of the material.

- Bend: Hands-on bend operations allow exploring new form possibilities and material properties.

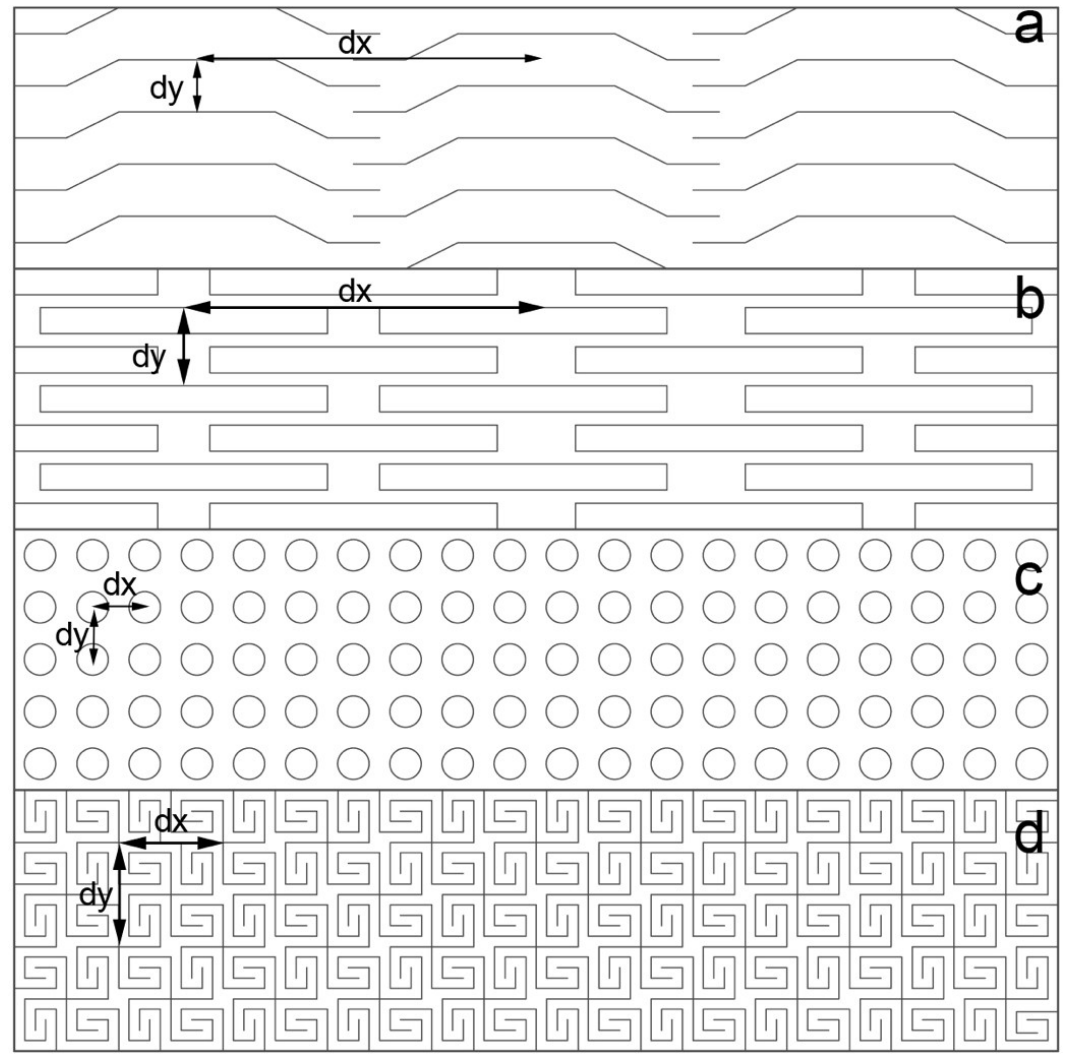

\section{EXPERIMENTATION PROCESS AND OBSERVATIONS}

The proposed model involves three phases: applying cut patterns and hands-on operations to two-dimensional planar material to observe the resulted material properties and three-dimensional form, translating threedimensional model to the two-dimensional pattern, and exploring new three-dimensional free form surfaces for improving the two-dimensional cut pattern algorithm (Figure 6).

The first phase starts with the design of two-dimensional cut patterns. Next, it applies two-dimensional CAD patterns onto 2-dimensional rigid planar materials via laser cut. Pattern design process starts with grid layout, which has a predefined size. A single geometry is overlapped on intersection points of grid layout as a one- or two-dimensional array organization. Variables such as the size of the pattern units, distance and direction between pattern elements and thickness are modified to explore the changing stiffness of the material (Figure 7).
Figure 5: The selected four cut patterns

Source: the authors 
Figure 6: Model diagram Source: the authors

Figure 7: Variations of four cut patterns

Source: the authors

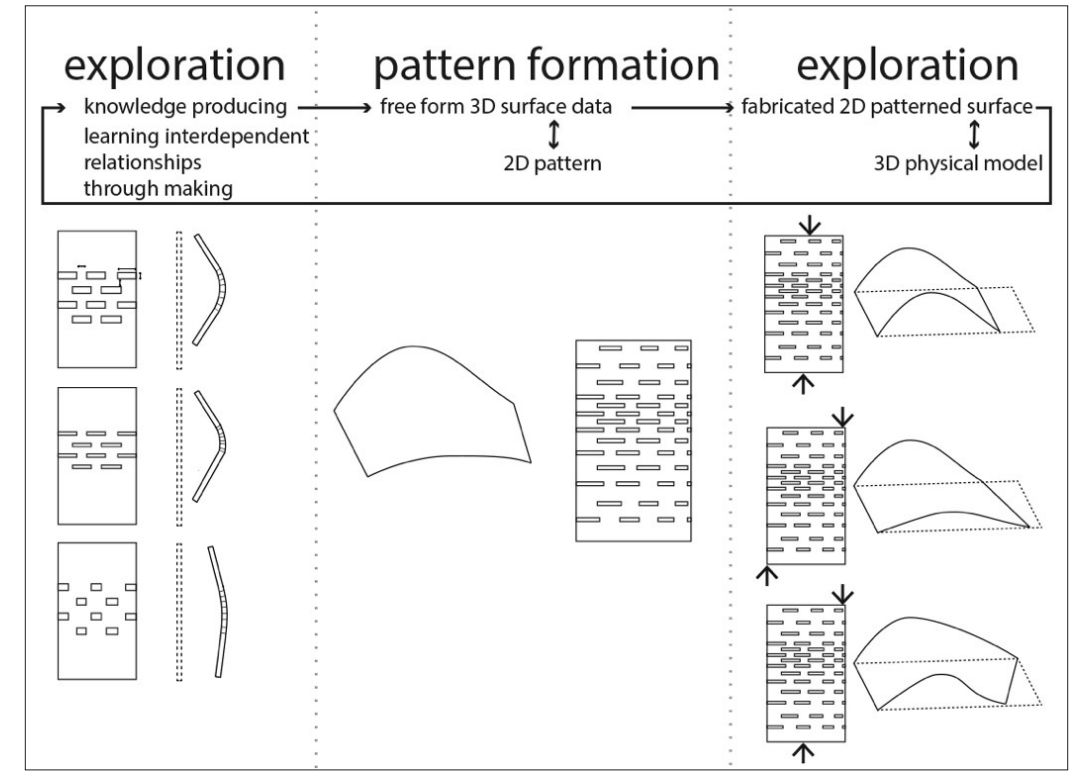


In the first phase, the following questions were investigated:

What is the relationship between pattern and flexibility of the material?

Do all isotropic materials behave in the same way?

How can we come up with the same 3D results with materials with different thicknesses?

What is the maximum bending limit of a material according to cut geometry?

One of the findings of this phase is that the porosity of the surface and the level of bending behaviors are not directly proportional. For example, in f4 (force directions of hands-on bending operations are shown in Figure 8 and Figure 9) void-solid area ratio of c1 surface is 1.01 (90.5 mm2/89.5mm2) and bending angle of $\mathrm{c} 1$ is 3 degrees. The properties for $\mathrm{d} 3$ are 1.23 (99.5mm2 / $80.5 \mathrm{~mm} 2$ ) and bending angle is 65 degrees.

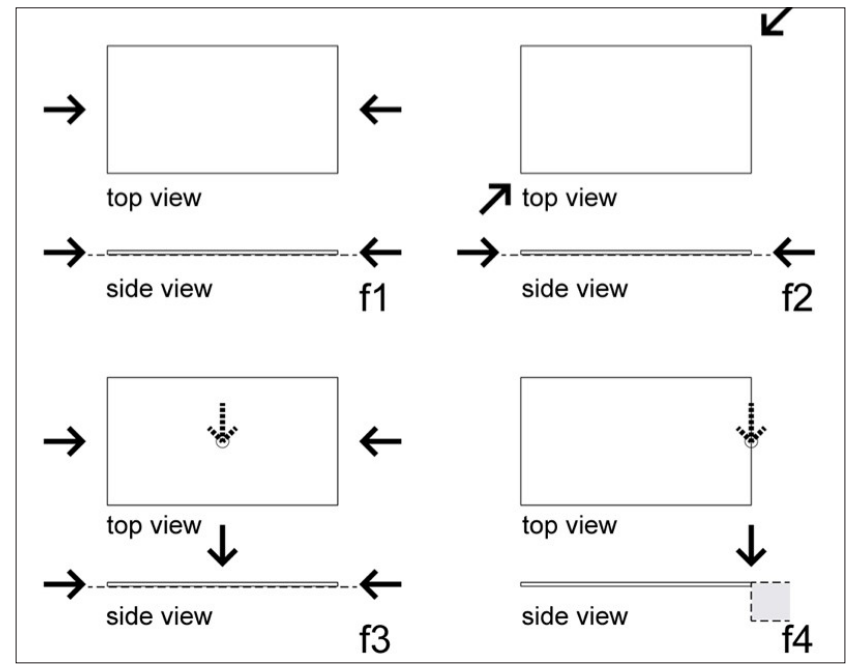

This result shows us that it is not the subtraction operation itself that increases the bending ability of the surface. However, decreasing the strength of the surface, especially in one direction through intertwining organization of the geometry, might increase the material flexibility. In that way, the planar surface begins to perform an anisotropic behavior. The planar surface that performed the maximum fabric-like bending behavior was $\mathrm{d} 3$, although the densities of the pattern in both $\mathrm{X}$ and $\mathrm{Y}$ directions were the same.

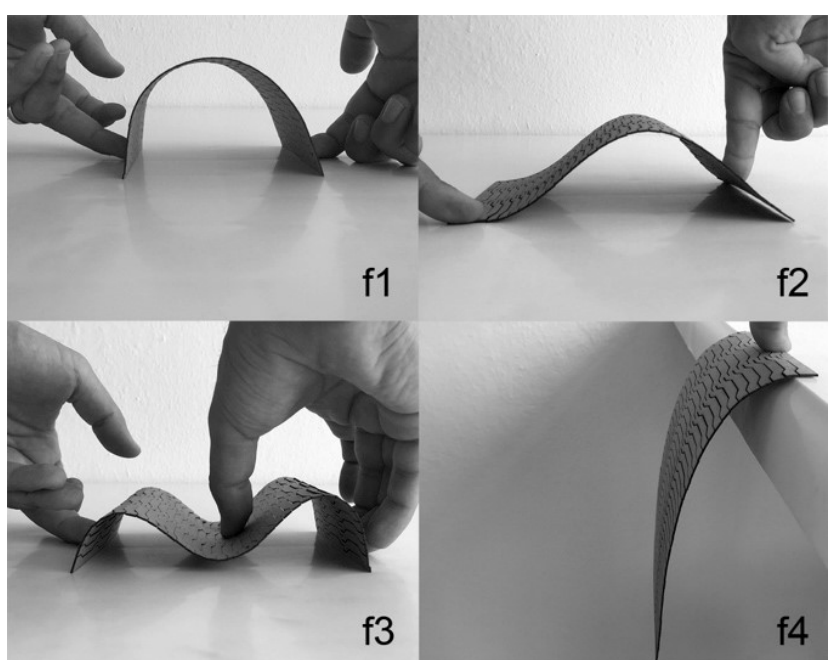

Figure 8: Operations and forces applied to the material

Source: the authors

Figure 9: Photos from explorations of a3 pattern

Source: the authors 
Figure 10: Comparison of bend behavior in different pattern variations

Source: the authors

Figure 11: Same f1 force applied to materials with different thicknesses

Source: the authors

Figure 12: Obliquity on the symmetry axis under forces Source: the authors

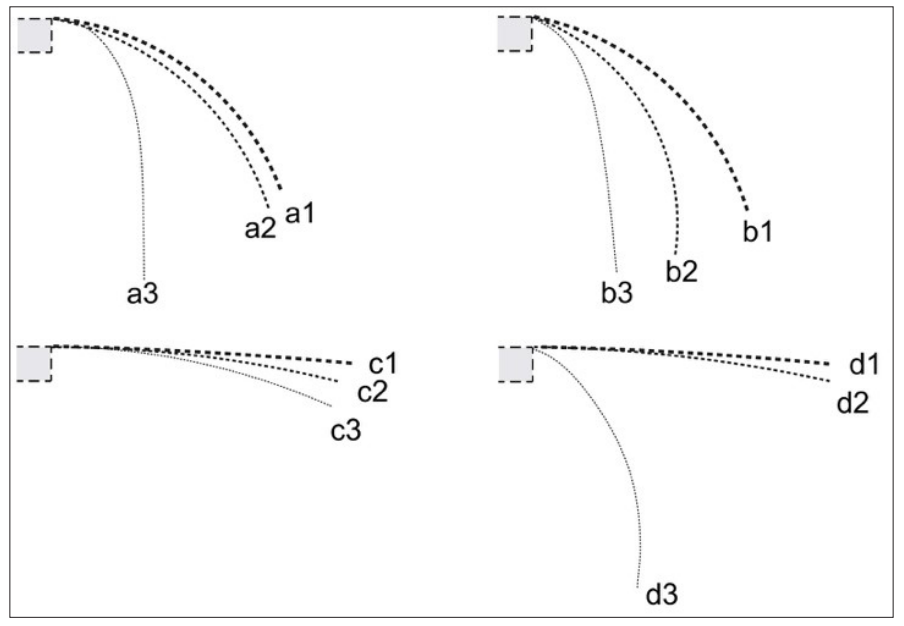

After experimenting with $1 \mathrm{~mm}$ and $2 \mathrm{~mm}$ cardboard materials, we also discovered that the bending behavior and bending angle are related to the plate thickness (Figure 10 and 11).

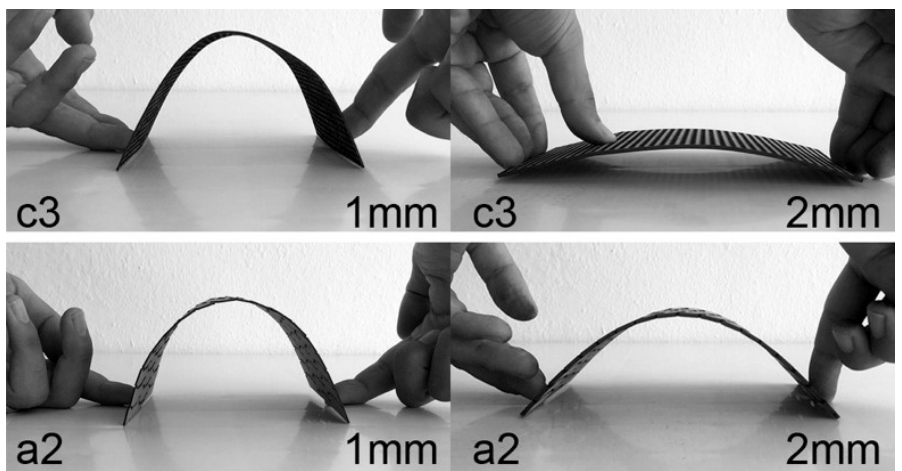

In the cases where hands-on experience is not used, bending behavior of a surface under $\mathrm{f} 1$ and $\mathrm{f} 2$ forces can be assumed as identical and symmetrical. In hands on exploration, hand movements cause deviations on symmetry axis (Figure 12). The obliquity in this modification is considered as an important parameter while transferring the information of analog model into the computational model (Figure 13).

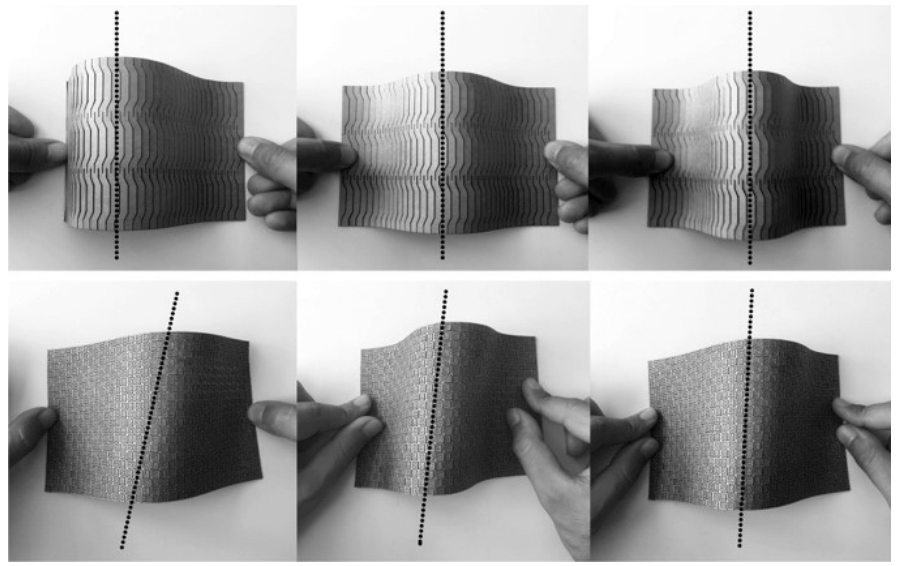

In order to model the relationship between the pattern, the local flexibility, and the obliquity of the surface, we started to program the 
relationship between the attraction curve and the dimension and position of the pattern elements in Rhinoceros/Grasshopper environment.

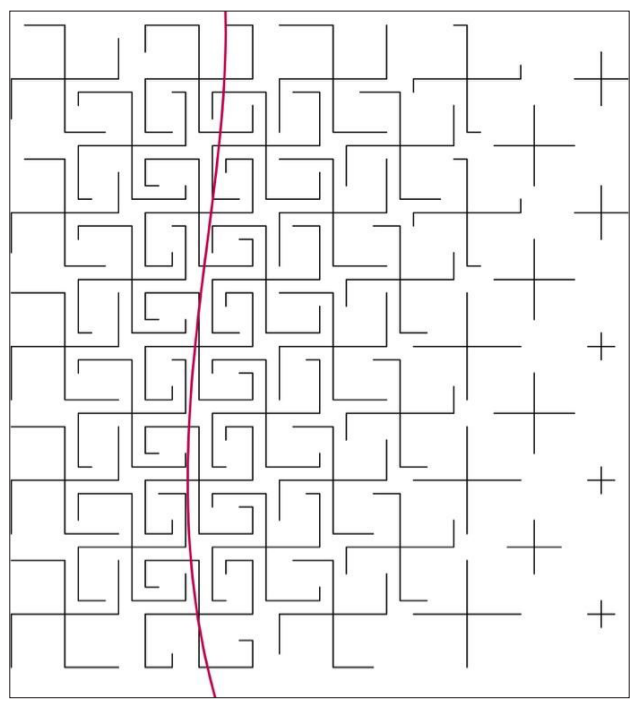

Understanding the relation between properties of the geometric pattern and properties of the material in an iterative way reveals the computational logic in this experimental dialog, which leads and informs the second phase. Among many trials, four patterns and their three variations were selected to exemplify these interdependent relations between geometric patterns and material property.

The second phase involves a series of reductions and new assumptions during the translation of curvature data into the digital environment. Inputs of this phase are an initial three-dimensional surface geometry with hills and valleys and also information derived from the first phase. The curvature of the three-dimensional surface and the parameters of the two-dimensional pattern are linked in the three-dimensional visual programming environment (Rhino/Grasshopper). According to the radius (curvature level) of the curves, the center point of pattern units are colored. The white points refer to valleys with the lowest slope and the black points refer to hills or holes with a higher curvature level. The numerical data based on the color coding derived from the curvature is used to change the local size parameters of the pattern cells. In the coding environment, number sliders are used to change the geometry and scale of pattern elements (Figure 14). Afterward, one of the selected patterns (Figure 7) is mapped onto the planar surface in different parameters derived from the curvature data of 3D surfaces. The thresholds in the change of the curvature of the surface are used as attraction curves.

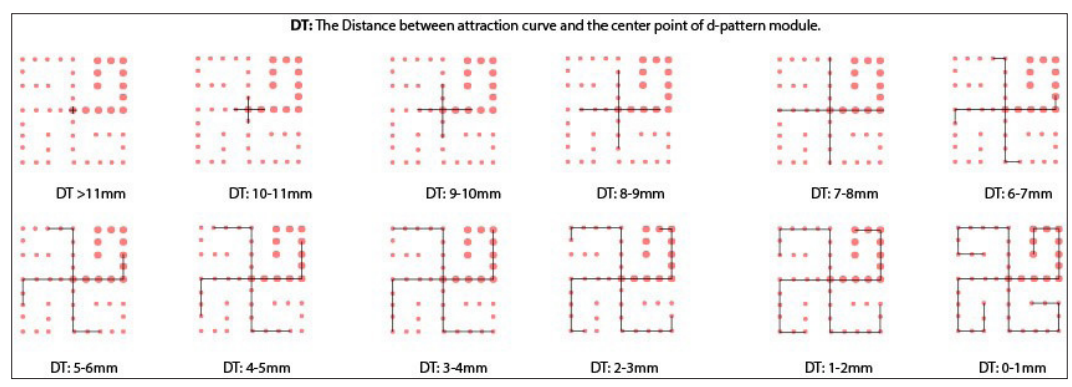

In other words, the curve connecting the inflection points on the 3D surface is projected onto the planar surface. This two-dimensional curve is assumed as an attraction curve to modify the selected 2D patterns (Figure 13 and Figure 15).
Figure 13: The modification of $d$-pattern based on bending axes of the surface

Source: the authors

Figure 14: Variations of the cells based on curvature data

Source: the authors 
Figure 15: Sample to color coding of valley and hills

Source: the authors

Figure 16: Three-dimensional form experiments based on three different attraction curves Source: the authors

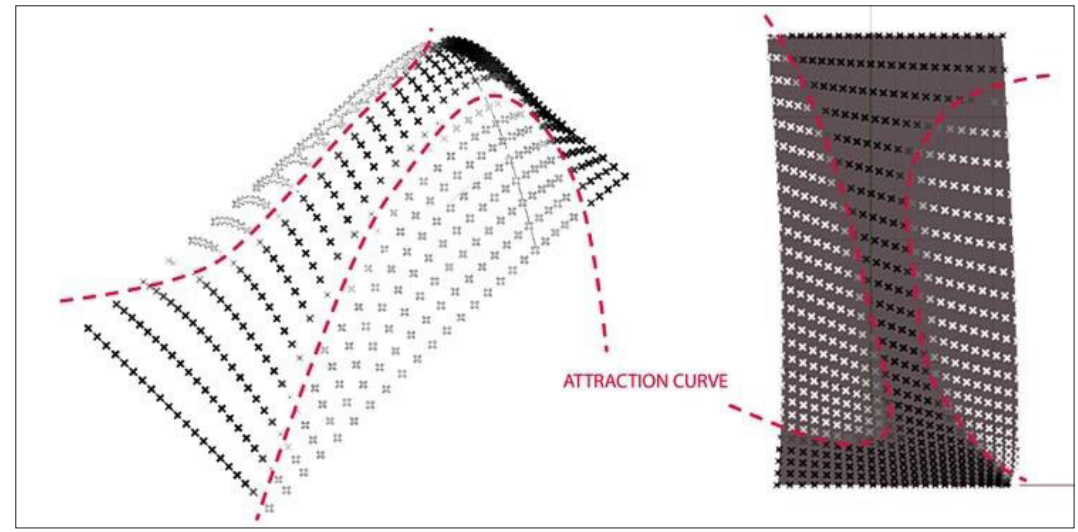

The third phase is hands-on exploration by using the laser cut productions to achieve various form possibilities. Outcomes of the second phase were used. Evenly, the two-dimensional pattern is generated with the information derived from the three-dimensional model. We observe that the hands-on exploration on the two-dimensional surface can generate new/various 3D surfaces (Figure 16). We aim to use this experimental phase to calibrate fabrication model and to develop more intricate algorithms for more precise models. Informed by the experiments shown in Figure 16, we calibrated the Grasshopper algorithm to develop a more precise relationship between the distribution of pattern on a panel and the intended local flexibility.

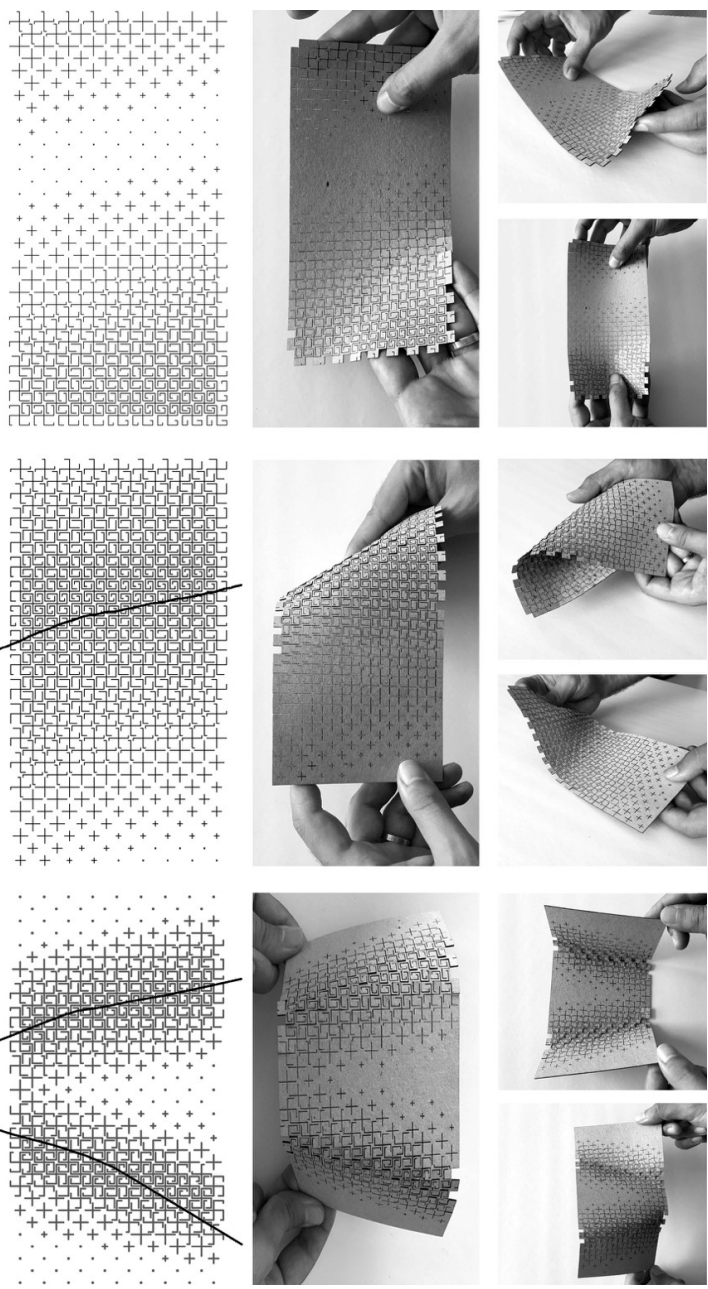


Following the experiments done in Figure 16, new material experiments were carried out using the pattern type as a variable. The same attractive curves and the same material were tested by applying three different patterns (Figure 17). Pattern-dependent results show that the spatial and scalar distribution of the pattern units in two-dimensional surface affects the material flexibility. However, beyond the spatial and scalar distribution of the units, local neighborhood relations of the units in the cutting pattern, topological relations of the units such as weaving organization influence the flexibility. In that sense, the units of the cut patterns shown in Figure 17, which do not carry out weaving attribute in comparison to the cut patterns used in Figure 16, have performed less flexibility during hands-on three-dimensional form explorations.

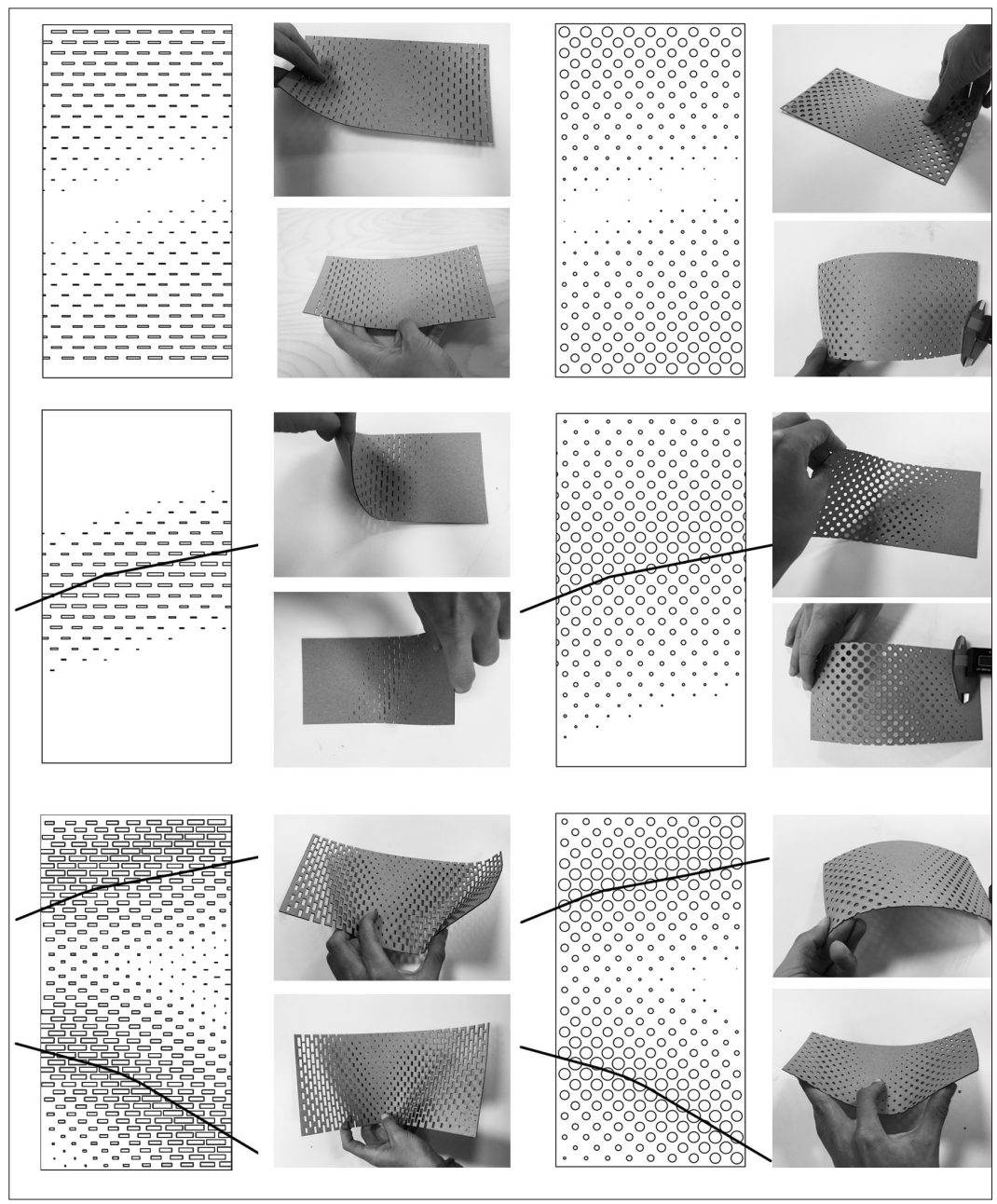

\section{DISCUSSION}

In this study, we focused on the question "How bending behavior become a generative tool for the computational process?”. With this interest, we aimed to gain experience from active experimentation during cyclic explorations on bending operation in both digital and physical media.

The experiments began with physical explorations instead of starting with digital ones. First, the design with two-dimensional patterns without knowing the result; second, the step by step evaluation relies on tacit tactile knowledge was conducted. The hands-on experience informs the logic of
Figure 17: Three-dimensional form experiments based on different patterns

Source: the authors 
the two-dimensional cut pattern algorithm. The observations and findings during the hands-on experimentation on two-dimensional planar surface feed not only to the typology of the three-dimensional digital model but also the organization of the geometry. Thus, it affects the two-dimensional cut pattern algorithm and further explorations on the bending behavior of threedimensional surface. In digital media, we defined the surface geometry based on two-dimensional array organizations and grid layout for pattern design. This grid layout itself became a limitation during the experiments. In the further studies, the manipulations of the grid organization might enrich the geometric pattern generation process and therefore, the bending behavior.

Outcomes produced during our experiments are study models rather than full-scale prototypes. Despite the fact that the material and geometrical constraints of the experimentation were so limited, the response of the materials to the cut pattern operations has been different than our initial assumptions. The real-time material behaviors affect the whole digital modeling and fabrication process from the very beginning of the explorations.

The study process can be summarized as research on enhancing the affordance of the planar material by using different cut operations through semi-structured experiments. Pattern type and attraction curves have been differentiated to examine the notions of diversity and complexity in relation with material behavior in the context of repeatable pedagogical approaches. While the dependency to the initial shape and its reflection to the bending performance of the material were observed, it is seen that the topological relations among the pattern units played an important role to affect flexibility of the planar material.

We argue that it is crucial to understand the logic of geometric organization in relation with material properties beyond merely threedimensional free form generation in the digital medium. It is because any relation learned from the material explorations would affect the whole fabrication process. Thus, the integration of analog and digital processes provides us the development of new possibilities for formal explorations informed by material properties.

Through exploring how properties and relations of two-dimensional geometric patterns allow bending behavior, it is possible to gain an insight on the relationship between two-dimensional and three-dimensional. Moreover, the model proposed in this study can be used as a pedagogical approach able to encourage not only the use of material techniques of cutting and bending, but also other techniques, such as twisting, folding, kerfing, stretching in an explorative and creative way for integrative design formation and fabrication processes.

\section{REFERENCES}

ACKERMANN, E. K. Experiences of artifacts. In: GLASERSFELD, E.; LAROCHELLE, M. (Ed.). Key works in radical constructivism. Rotterdam: Sense Publishers, 2007. p. 249-259.

AISH, R. First build your tools. In: PETERS, B.; PETERS, T. (Eds.). Inside smartgeometry: expanding the architectural possibilities of computational design. Hoboken: Wiley, 2013. p. 36-49

D'ACUNTO, P.; KOTNIK, T. AA/ETHPavilion. In: TENSINET SYMPOSIUM, 2013, Istanbul. Proceedings... Istanbul: TensiNet Association, 2013. p. 99-108.

DEWEY, J. Logic: the theory of inquiry. New York: Henry Holt and Company, 1938.
GREENBERG, E.; KÖRNER, A. Subtractive manufacturing for variable-stiffness plywood composite structures. In: INTERNATIONAL CONFERENCE ON SUSTAINABLE DESIGN AND MANUFACTURING, 2014. Proceedings... Cardiff: Cardiff University, 2014. p. 50-66.

HOFFER, B. et al. Kerf Pavilion. [S.I.]: IAP Pavilion Competition, 2012. Disponível em: <https://goo.gl/Q5TSLb>. Acesso em: 15 nov. 2016

KOTELNIKOVA-WEILER, N. et al. Materials for actively-bent structures. International Journal of Space Structures, Thousand Oaks, v. 28, n. 3-4, p. 229-240, 2013. 
KOTNIK, T.; WEINSTOCK, M. Material, form and force. Architectural Design, Hoboken, v. 82, n. 2, p. 104-111, 2012.

MOHOLY-NAGY, L. The new vision: fundamentals of bauhaus design, painting, sculpture, and architecture. New York: Dover Publications, 2005.

MUÑOZ, P. Diseño Basado en Investigación. In: CONGRESO DE LA SOCIEDAD IBEROAMERICANA DE GRÁFICA DIGITAL, 17,. 2013, Valparaíso. Anales... Valparaíso: Universidad Técnica Federico Santa Maria, 2013. p. 435-438.

NABONI, R.; MIRANTE, L. Desenho computacional e simulação de estruturas auxéticas de flexão-ativa. Gestão e Tecnologia de Projetos, São Carlos, v. 11, n. 2, p. 59-72, 2016.

NABONI, R.; PEZZI, S. S. Embedding auxetic properties in designing activebending gridshells. In: CONGRESS OF THE IBEROAMERICAN SOCIETY OF DIGITAL GRAPHICS, 20., 2016, Buenos Aires. Proceedings... Buenos Aires: Sociedade Iberoamerıcana de Gráfica Digital, 2016. p. 720-726.
PUGH, K. J.; GIROD, M. Science, art, and experience: constructing a science pedagogy from Dewey's aesthetics. Journal of Science Teacher Education, New York, v. 18, n. 1, p. 9-27, 2007.

SCHÖN, D. A. Learning to design and designing to learn. Nordisk Arkitekturforskning, Lund, n. 1, p. 55-70, 1993.

SCHÖNBRUNNER, A. et al. Design strategies for bending-active plate structures out of multiple cross-connected layers. In: PROCEEDINGS OF THE INTERNATIONAL ASSOCIATION FOR SHELL AND SPATIAL STRUCTURES, 2015, Amsterdam. Proceedings... Amsterdam: IASS, 2015.

WESTON, M. Anisotropic operations. International Journal of Architectural Computing, Thousand Oaks, v. 10, n. 1, p. 105-120, 2012

ZARRINMEHR, S. et al. Interlocked archimedean spirals for conversion of planar rigid panels into locally flexible panels with stiffness control. Computers \& Graphics Amsterdam, v. 66, p. 93-102, 2017.
Orkan Zeynel Güzelci orkanguzelci@gmail.com

Sema Alaçam

semosphere@gmail.com

Saadet Zeynep Bacınoğlu zeynepbacinoglu@gmail.com 